\title{
FEEDING HABITS OF THE SEAHORSE HIPPOCAMPUS PATAGONICUS (ACTINOPTERYGII: SYNGNATHIFORMES: SYNGNATHIDAE) ON THE SOUTHERN COAST OF BRAZIL
}

\author{
Luci F. PEREIRA ${ }^{1}$, Rosana B. SILVEIRA², and Vinícius ABILHOA ${ }^{1,3^{*}}$ \\ ${ }^{1}$ Zoology Graduate Program, Federal University of Paraná, Curitiba PR, Brazil \\ ${ }^{2}$ Marine Aquaculture Laboratory (LABAQUAC), Projeto Hippocampus, Porto de Galinhas, Ipojuca PE, Brazil \\ ${ }^{3}$ GPIc, Capão da Imbuia Natural History Museum, Curitiba PR, Brazil
}

\begin{abstract}
Pereira L.F., Silveira R.B., Abilhoa V. 2018. Feeding habits of the seahorse Hippocampus patagonicus (Actinopterygii: Syngnathiformes: Syngnathidae) on the southern coast of Brazil. Acta Ichthyol. Piscat. 48 (3): $267-271$.

Abstract. The feeding habits of the seahorse Hippocampus patagonicus Piacentino et Luzzatto, 2004 on the southern Brazilian coast was evaluated through the gut content analysis of 82 individuals $(28-110 \mathrm{~mm}$ in height, HT) obtained through a fish landing monitoring program (July 2011 to November 2012). Results showed that $H$. patagonicus feed mainly on small benthic and pelagic zooplankton organisms, mainly amphipods, decapods postlarvae (megalopa), and isopods. In the warm season $\left(>20^{\circ} \mathrm{C}\right.$, from November to April) the diet was dominated by amphipods, and in the cold season $\left(<19^{\circ} \mathrm{C}\right.$, from May to October) by decapods post-larvae and isopods. No significant differences were observed on the diet composition of juveniles $(<48.5 \mathrm{~mm}$ HT) and adults $(>48.5 \mathrm{~mm}$ HT) and also among sites. The importance of amphipods and decapod larvae as a food source is well known for seahorses, all explained by their highly specialized prey-capture mechanism and foraging behaviour.
\end{abstract}

Keywords: Crustacea, diet, South-western Atlantic, threatened species

\section{INTRODUCTION}

Seahorses are small teleost fishes with highly specialized morphology and life history (Lourie et al. 2016). They are members of the family Syngnathidae, which also includes pipefishes, pipehorses, and seadragons (Nelson et al. 2016). They are distributed worldwide in marine and estuarine shallow waters of tropical and temperate regions of the Pacific, Atlantic, and Indian oceans (Lourie et al. 1999, Vincent et al. 2011). Several species of seahorses were assessed for the IUCN Red List of Threatened Species and are currently considered threatened as result of habitat loss and degradation, overfishing (bycatch), aquarium trade, and collection for medicinal and religious purposes (Anonymous 2018).

Information available on the feeding habits of seahorses from field-based studies (Tipton and Bell 1988, Kanou and Kohno 2001, Teixeira and Musick 2001, Woods 2002, Kendrick and Hyndes 2005, Castro et al. 2008, Felício et al. 2006, Kitsos et al. 2008, Storero and González 2008, Valladares et al. 2016) indicates an opportunistic and specialized predatory strategy, based primarily on plankton and small crustaceans. Since seahorses are slow swimmers and usually anchor themselves to a substrate, such kind of evasive prey is captured by an unusual preycapture behaviour known as pivot feeding (de Lussanet and Muller 2007). This feeding strategy consists in a rapid upward rotation of the head toward the prey whilst slurping (Gemmell et al. 2013). The long snout generates a flow of water that draws the prey into the mouth (suction), and this process differs from what is typically observed in suction-feeding teleost fishes (Van Wassenbergh and Aerts 2008). The suction-feeding strategy in seahorses has been linked to the possession of a pipette-like feeding structure (Bergert and Wainwright 1997) and associated morphological specializations (Van Wassenbergh et al. 2011, 2013), including a well-developed acute visual system (Lee and O'Brien 2011).

In the presently reported study, we evaluated the diet composition of Hippocampus patagonicus Piacentino et Luzzatto, 2004 in the southern coast of Brazil, and its variability due to a stage of development, sites and season. The seahorse H. patagonicus is the southernmost seahorse in the South Atlantic Ocean (Piacentino and Luzzatto 2004, González et al. 2014), listed as 'Vulnerable' on the IUCN Red List of Threatened Species (Wei et al. 2017).

\section{MATERIAL AND METHODS}

Specimens of Hippocampus patagonicus were obtained through a fish landing monitoring program that targets the bycatch of the industrial trawl fishery on the

* Correspondence: Dr. Vinícius Abilhoa, Museu de História Natural Capão da Imbuia, Prefeitura de Curitiba, Rua Prof. Benedito Conceição 407, CEP 82810-080, Curitiba, PR, Brazil, phone: (+55) 4132670819, e-mail: (VA) vabilhoa@uol.com.br, (LFP)lucifpereira27@gmail.com, (RBS)labaquac@yahoo.com. 
southern Brazilian coast, in three landing sites in the State of Rio Grande do Sul: Torres $\left(29^{\circ} 20^{\prime} \mathrm{S}, 4^{\circ} 43^{\prime} \mathrm{W}\right)$, Tramandaí $\left(29^{\circ} 59^{\prime} \mathrm{S}, \quad 50^{\circ} 08^{\prime} \mathrm{W}\right)$, and Rio Grande $\left(32^{\circ} 01^{\prime} \mathrm{S}, 52^{\circ} 05^{\prime} \mathrm{W}\right)$ (Fig. 1). Sites were visited monthly from July 2011 to November 2012. The incidental capture of seahorses occurred between the 10 and $25 \mathrm{~m}$ isobaths.

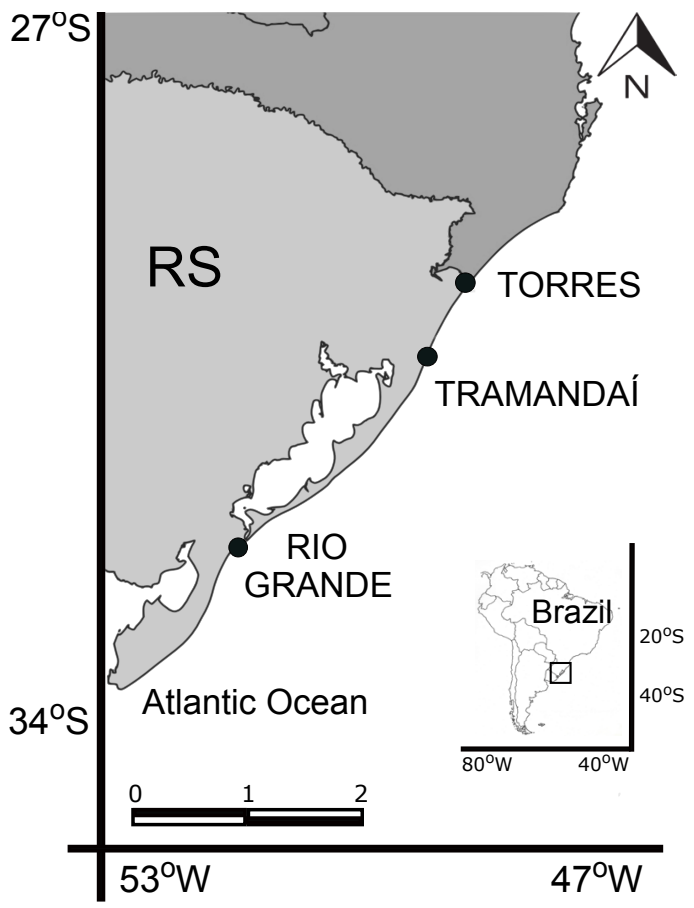

Fig. 1. Location of the three-trawl fishery landing sites (Torres, Tramandaí, and Rio Grande) along the State of Rio Grande do Sul coastal region (Southern coast of Brazil)

Seahorses were stored on ice and transferred to the laboratory where they were kept until examined. In the laboratory, the height (HT) (distance from the top of the coronet to the tip of elongated tail) of each individual was measured to the nearest $0.01 \mathrm{~mm}$ using a digital calliper and then they were dissected under a stereomicroscope (Lourie et al. 2004). Individuals were classified in two stages of development: juvenile $(<48.5 \mathrm{~mm})$ and adult $(>48.5 \mathrm{~mm})$, according to the presence and development state of brood pouch (Foster and Vincent 2004) and the macroscopic evaluation of gonads, using a macroscopic staging system based on gonad size, colour, vascularization, and the presence of identifiable oocytes (Brown-Peterson et al. 2011). The digestive tract was removed, sectioned at the constriction (sphincter) that separates the foregut (stomach) from the midgut (intestine) (Yip et al. 2014), and transferred to $70 \%$ ethanol for conservation. After that, the stomachs were dissected for food items analyses.

Food items were counted and identified to the lowest possible taxonomic level according to specific literature (Chapman 2007), and classified into two major categories: benthic (organisms that live in or near the marine substrate) and pelagic preys (organisms that live in the pelagic zone, characterized by adaptations that make possible buoyancy and motility). Diet composition was then estimated by the frequency of occurrence (FO\%, percentage of stomachs in which a food item occurs considering all stomachs examined) and the numeric frequency (FN\%, the percentage participation of each item in relation to the total abundance of preys) methods (Hyslop 1980).

Variations on the diet composition according to the stage of development (juvenile, adult), sites (Torres, Tramandaí, and the Rio Grande), and seasons (cold, warm) were assessed with permutational multivariate analyses of variance (PERMANOVA). Cold $\left(<19^{\circ} \mathrm{C}\right.$, from May to October) and warm $\left(>20^{\circ} \mathrm{C}\right.$, from November to April) seasons were characterized based on temperature historical data (January 1964 to August 2015) provided by INMET (National Institute of Meteorology). PERMANOVA (999 permutations under a reduced model) were performed by the PRIMER v. 6.1 .13 ® with PERMANOVA + 1.0.3 add-on package software*, using stomachs as replicates and the stage of development, sites and seasons as fixed factors. A similarity matrix was constructed using the Bray-Curtis coefficient based on the standardized and transformed $(\log X+1)$ values of the abundance of food items.

\section{RESULTS}

A total of 82 individuals ( 25 juveniles and 57 adults) of Hippocampus patagonicus were measured, ranging from 28 to $110 \mathrm{~mm}$ HT (mean \pm standard deviation $=56.6$ $\pm 17.6 \mathrm{~mm})$. Only $57(69.5 \%)$ stomachs contained prey items, and the vacuity rate (proportion of empty stomachs) was therefore $30.5 \%$. Among the stomachs with content, $22(38.6 \%)$ belong to juveniles (HT mean $\pm \mathrm{SD}=40.4$ $\pm 7.7 \mathrm{~mm}$ ) and $35(61.4 \%)$ to adults (HT mean $\pm \mathrm{SD}=$ $66.8 \pm 13.9 \mathrm{~mm}, 14$ females and 21 males). Identifiable prey items included organisms representing Crustacea (Amphipoda, Isopoda, Tanaidacea, Copepoda, Decapoda, and Ostracoda), Annelida, Foraminifera, and Nematoda. Algae fragments were recorded in small quantities and most probably represent accidental ingestion during prey capture. PERMANOVA analysis revealed significant differences between seasons (Pseudo- $F=2.99, P=0.04$, Unique perms $=985)$, but no differences were observed between sites (Pseudo- $F=1.55, P=0.11$, Unique perms $=998$ ) and stages of development (Pseudo- $F=0.97, P=$ 0.39 , Unique perms $=999$ ). According to the frequency of occurrence and the numeric frequency of food item, in the warm season, the diet recorded in 42 stomachs was dominated by amphipods, mostly Dexaminidae and unidentified Gammaridea, and in the cold season $(N=15)$ by Decapoda megalopa and Dendobranchiata, and also Isopoda (Gnathia) (Table 1).

\section{DISCUSSION}

The presently reported study revealed that Hippocampus patagonicus feed largely on small benthic and pelagic zooplankton organisms, mainly amphipods, decapod post-larvae (megalopa), and isopods. The high 
Table 1

Diet composition of Hippocampus patagonicus from South Atlantic expressed in frequency of occurrence (FO\%) and numeric percentage (FN\%)

\begin{tabular}{|c|c|c|c|c|c|c|c|}
\hline \multirow{3}{*}{ Higher taxa } & \multirow{3}{*}{ Food item } & \multirow{3}{*}{$N$} & \multirow{3}{*}{$\begin{array}{l}\text { Ecological } \\
\text { category }\end{array}$} & \multicolumn{4}{|c|}{ Season } \\
\hline & & & & Warm & Warm & Cold & Cold \\
\hline & & & & $\mathrm{FO} \%$ & $\mathrm{FN} \%$ & $\mathrm{FO} \%$ & FN\% \\
\hline \multirow{7}{*}{$\begin{array}{l}\text { CRUSTACEA } \\
\text { Class Malacostraca } \\
\text { Order Amphipoda } \\
\text { Suborder Gammaridea }\end{array}$} & Crustacea gen sp. & 54 & $?$ & 40.82 & 27.72 & 12.5 & 10.34 \\
\hline & Aoridae gen sp. & 3 & $\mathrm{~B}$ & 2.04 & 0.54 & 12.5 & 6.90 \\
\hline & Hyalidae gen sp. & 2 & B & 4.08 & 1.09 & - & - \\
\hline & Isaeidae gen sp. & 1 & B & 2.04 & 0.54 & - & - \\
\hline & Dexaminidae gen sp. & 56 & B & 24.49 & 30.43 & - & - \\
\hline & Ischyroceridae gen sp. & 6 & B & 10.2 & 3.26 & - & - \\
\hline & Ampithoidae gen sp. & 4 & $\mathrm{~B}$ & 2.04 & 2.17 & - & - \\
\hline Suborder Hyperiidea & Lestrigonus spp. & 24 & $\mathrm{P}$ & 6.12 & 12.50 & 12.5 & 3.45 \\
\hline \multirow[t]{2}{*}{ Order Isopoda } & Munna spp. & 1 & B & 2.04 & 0.54 & - & - \\
\hline & Gnathia spp. & 11 & $\mathrm{~B}$ & 2.04 & 0.54 & 12.5 & 34.48 \\
\hline Order Tanaidacea & Paratanaidae gen sp. & 1 & $\mathrm{~B}$ & 2.04 & 0.54 & - & - \\
\hline \multirow[t]{2}{*}{ Order Decapoda } & megalopa & 22 & $\mathrm{P}$ & 14.29 & 5.98 & 50.0 & 37.93 \\
\hline & Dendrobranchiata gen sp. & 8 & $\mathrm{P}$ & 10.2 & 3.26 & 25.0 & 6.90 \\
\hline \multicolumn{8}{|l|}{ Class Maxillopoda } \\
\hline Subclass Copepoda & Harpacticoida gen sp. & 3 & $\mathrm{~B}$ & 4.08 & 1.63 & - & 一 \\
\hline Class Ostracoda & Ostracoda gen sp. & 1 & $\mathrm{~B}$ & 2.04 & 0.54 & - & - \\
\hline ANNELIDA & Polychaeta gen sp. & 1 & $\mathrm{~B}$ & 2.04 & 0.54 & - & - \\
\hline FORAMINIFERA & Cribroelphidium cf. poeyanum & 2 & $\mathrm{~B}$ & 2.04 & 1.09 & - & - \\
\hline \multirow[t]{2}{*}{ NEMATODA } & Nematoda gen sp. & 1 & $\mathrm{~B}$ & 2.04 & 0.54 & - & - \\
\hline & VEGETAL & 11 & $?$ & 20.41 & 5.98 & - & - \\
\hline
\end{tabular}

$N=$ total abundance of prey, $\mathrm{B}=$ benthic, $\mathrm{P}=$ pelagic.

consumption of amphipods was also reported by Storero and González (2008) for $H$. patagonicus in its southernmost known population of Argentina (Santo Antonio Bay), and also for others seahorses species (Burchmore et al. 1984, Teixeira and Musick 2001, Woods 2002, Kendrick and Hyndes 2005, Kitsos et al. 2008, Gurkan et al. 2011, Yip et al. 2014). In fact, amphipods are one of the most common prey items of many benthic-feeding fishes (Wakabara et al. 1982). They are a diverse and abundant group of peracaridean crustaceans that inhabit a variety of benthic substrata (Thomas 1993), and their density and geographic distribution are highly influenced by hydrodynamic conditions (Rodrigues et al. 2012, Maria et al. 2016).

According to Storero and González (2008), H. patagonicus feed on a broad spectrum of crustacean's organisms, mainly amphipods (Gammaridae and Caprellidae) and planktonic larvae of decapods (particularly, Brachyura and Caridea). Even considering that the identity of preys varied considerably between our study and those of Storero and González (2008), such variations in the dietary composition appear to be related to the prey availability.

Contrary to our expectations, the diet composition of $H$. patagonicus did not differ significantly among the three landing sites, even though the distribution and spatial variability of zooplankton organisms along the Brazilian coast are highly influenced by local and regional hydrodynamic conditions (Lopes 2007). We believe that this result was influenced by the taxonomic resolution of prey categories on the analyses (Pombo et al. 2013), since amphipods and decapod post-larvae were incompletely identified because of the degree of digestion, and also by the overlap of industrial trawl fishing grounds in southern Brazil.

\section{ACKNOWLEDGEMENTS}

The authors are thankful to the artisanal fishers of Rio Grande, Tramandaí, and Torres for their valuable collaboration and Sibele Disaró for Foraminifera identification. We especially want to acknowledge all reviewers for their valuable suggestions that improved the manuscript. This work is a contribution of the Projeto Hippocampus (www.projetohippocampus.org), with financial support from Petrobras.

\section{REFERENCES}

Anonymous 2018. The IUCN Red List of Threatened Species. Version 2017-3. [Downloaded on 19 March 2018.] www.iucnredlist.org

Bergert B.A., Wainwright P.C. 1997. Morphology and kinematics of prey capture in the syngnathid fishes Hippocampus erectus and Syngnathus floridae. Marine Biology 127 (4): 563-570. DOI: 10.1007/ s002270050046

Brown-Peterson N.J., Wyanski D.M., Saborido-Rey F., Macewicz B.J., Lowerre-Barbieri S.K. 2011. A standardized terminology for describing reproductive development in fishes. Marine and Coastal Fisheries 3 (1): 52-70. DOI: 10.1080/19425120.2011.555724 
Burchmore J.J., Pollard D.A., Bell J.D. 1984. Community structure and trophic relationships of the fish fauna of an estuarine Posidonia australis seagrass habitat in Port Hacking, New South Wales. Aquatic Botany 18 (1-2): 71-87. DOI: 10.1016/03043770(84)90081-0

Castro A.L.C., Diniz A.F., Martins I.Z., Vendel A.L., Oliveira T.P.R., Rosa I.M.L. 2008. Assessing diet composition of seahorses in the wild using a nondestructive method: Hippocampus reidi (Teleostei: Syngnathidae) as a study-case. Neotropical Ichthyology 6 (4): 637-644. DOI: 10.1590/S167962252008000400012

Chapman L.J. 2007. Amphipoda: Gammaridea. Pp. 545618. In: James C.T. (ed.) The light and Smith manual: Intertidal invertebrates from central California to Oregon, Completely revised and expanded. 4th edn. University of California Press, Berkeley, CA, USA.

de Lussanet M.H.E., Muller M. 2007. The smaller your mouth, the longer your snout: Predicting the snout length of Syngnathus acus, Centriscus scutatus and other pipette feeders. Journal of the Royal Society Interface 4 (14): 561-573. DOI: 10.1098/ rsif.2006.0201

Felício A.K.C., Rosa I.L., Souto A., Freitas R.H.A. 2006. Feeding behavior of the longsnout seahorse Hippocampus reidi Ginsburg, 1933. Journal of Ethology 24 (3): 219-225. DOI: 10.1007/s10164-005-0189-8

Foster S.J., Vincent C.J. 2004. Life history and ecology of seahorses: Implications for conservation and management. Journal of Fish Biology 65 (1): 1-61. DOI: 10.1111/j.0022-1112.2004.00429.x

Gemmell B.J., Sheng J.W., Buskey E.J. 2013. Morphology of seahorse head hydrodynamically aids in capture of evasive prey. Nature Communications 4 : e2840. DOI: $10.1038 /$ ncomms 3840

González R., Dinghi P., Corio C., Medina A., Maggioni M., Storero L., Gosztonyi A. 2014. Genetic evidence and new morphometric data as essential tools to identify the Patagonian seahorse Hippocampus patagonicus (Pisces, Syngnathidae). Journal of Fish Biology 84 (2): 459-474. DOI: 10.1111/jfb.12299

Hyslop E.J. 1980. Stomach contents analysis - a review of methods and their application. Journal of Fish Biology 17 (4): 411-429. DOI: 10.1111/j.10958649.1980.tb02775.x

Kanou K., Kohno H. 2001. Early life history of a seahorse, Hippocampus mohnikei, in Tokyo Bay, Japan. Ichthyological Research 48 (4): 361-368. DOI: 10.1007/s 10228-001-8159-9

Kendrick A.J., Hyndes G.A. 2005. Variations in the dietary compositions of morphologically diverse syngnathid fishes. Environmental Biology of Fishes 72 (4): 415-427. DOI: 10.1007/s10641-004-2597-y

Kitsos M.-S., Tzomos T., Anagnostopoulou L., Koukouras A. 2008. Diet composition of the seahorses, Hippocampus guttulatus Cuvier, 1829 and Hippocampus hippocampus (L., 1758) (Teleostei, Syngnathidae) in the Aegean Sea. Journal of Fish
Biology 72 (6): 1259-1267. DOI: 10.1111/j.10958649.2007.01789.x

Lee H.R., O'Brien K.M.B. 2011. Morphological and behavioral limit of visual resolution in temperate (Hippocampus abdominalis) and tropical (Hippocampus taeniopterus) seahorses. Visual Neuroscience 28 (4): 351-360. DOI: 10.1017/ S0952523811000149

Lopes R.M. 2007. Marine zooplankton studies in Brazil-A brief evaluation and perspectives. Anais da Academia Brasileira de Ciências 79 (3): 369-379. DOI: 10.1590/S0001-37652007000300002

Lourie S.A., Pritchard J.C., Casey S.P., Truong S.K., Hall H.J., Vincent A.C.J. 1999. The taxonomy of Vietnam's exploited seahorses (family Syngnathidae). Biological Journal of the Linnean Society 66 (2): 231 256. DOI: 10.1111/j.1095-8312.1999.tb01886.x

Lourie S.A., Foster S.J., Cooper E.W.T., Vincent A.C.J. 2004. A guide to the identification of seahorses. University of British Columbia, Vancouver, BC, Canada and World Wildlife Fund, Washington DC, USA.

Lourie S.A., Pollom R.A., Foster S.J. 2016. A global revision of the seahorses Hippocampus Rafinesque 1810 (Actinopterygii: Syngnathiformes): Taxonomy and biogeography with recommendations for further research. Zootaxa 4146 (1): 1-66. DOI: 10.11646/ zootaxa.4146.1.1

Maria T.F., Wandeness A.P., Esteves A.M. 2016. State of the art of the meiofauna of Brazilian sandy beaches. Brazilian Journal of Oceanography 64 (2): 17-26. DOI: $10.1590 /$ S1679-875920160946064sp2

Nelson J.S., Grande T.C., Wilson M.V.H. 2016. Fishes of the world. 5th edn. John Wiley and Sons, Hoboken NJ, USA.

Piacentino G.L.M., Luzzatto D.C. 2004. Hippocampus patagonicus sp. nov., nuevo caballito de mar para La Argentina (Pisces, Syngnathiformes). Revista del Museo Argentino de Ciencias Naturales 6 (2): 339 349.

Pombo M., Denadai M.R., Turra A. 2013. Seasonality, dietary overlap and the role of taxonomic resolution in the study of the diet of three congeneric fishes from a tropical bay. PLoS One 8 (2): e56107. DOI: 10.1371/ journal.pone.0056107

Rodrigues C.W., Pires-Vanin A.M.S. 2012. Spatiotemporal and functional structure of the amphipod communities off Santos, Southwestern Atlantic. Brazilian Journal of Oceanography 60 (3): 421-439. DOI: $10.1590 / \mathrm{S} 1679-87592012000300013$

Storero L.P., González R.A. 2008. Feeding habits of the seahorse Hippocampus patagonicus in San Antonio Bay (Patagonia, Argentina). Journal of the Marine Biological Association of the United Kingdom 88 (7): 1503-1508. DOI: 10.1017/S0025315408002506

Teixeira R.L., Musick J.A. 2001. Reproduction and food habits of the lined seahorse, Hippocampus erectus (Teleostei: Syngnathidae) of Chesapeake Bay, Virginia. Revista Brasileira de Biologia 61 (1): 79-90. DOI: $10.1590 / \mathrm{S} 0034-71082001000100011$ 
Thomas J.D. 1993. Biological monitoring and tropical biodiversity in marine environments: A critique with recommendations, and comments on the use of amphipods as bioindicators. Journal of Natural History 27 (4): 795-806. DOI: 10.1080/00222939300770481

Tipton K., Bell S.S. 1988. Foraging patterns of two syngnathid fishes: Importance of harpacticoid copepods. Marine Ecology Progress Series 47: 31-43. DOI: $10.3354 /$ meps047031

Valladares S., Soto D.X., Planas M. 2016. Dietary composition of endangered seahorses determined by stable isotope analysis. Marine and Freshwater Research 68 (5): 831-839. DOI: 10.1071/MF16013

Vincent A.C.J., Foster S.J., Koldewey H.J. 2011. Conservation and management of seahorses and other Syngnathidae. Journal of Fish Biology 78 (6): 1681724. DOI: 10.1111/j.1095-8649.2011.03003.x

Van Wassenbergh S., Aerts P. 2008. Rapid pivot feeding in pipefish: Flow effects on prey and evaluation of simple dynamic modelling via computational fluid dynamics. Journal of the Royal Society Interface 5: 1291-1301. DOI: 10.1098/rsif.2008.0101

Van Wassenbergh S., Leysen H., Adriaens D., Aerts P. 2013. Mechanics of snout expansion in suctionfeeding seahorses: Musculoskeletal force transmission. Journal of Experimental Biology 216: 407-417. DOI: 10.1242/jeb.074658
Van Wassenbergh S., Roos G., Aerts P., Herrel A., Adriaens D. 2011. Why the long face? A comparative study of feeding kinematics of two pipefishes with different snout length. Journal of Fish Biology 78 (6): 1786-1798. DOI: 10.1111/j.1095-8649.2011.02991.x

Wakabara Y., de Rezende E.K., Tararam A.S. 1982. Amphipods as one of the main food components of three Pleuronectiformes from the continental shelf of south Brazil and north Uruguay. Marine Biology 68 (1): 67-70. DOI: 10.1007/BF00393142

Wei J., Estalles M., Pollom R., Luzzatto D. 2017. Hippocampus patagonicus. The IUCN Red List of Threatened Species 2017: e.T195100A54909767. [Downloaded on 18 September 2018] DOI: 10.2305/ IUCN.UK.2017-3.RLTS.T195100A54909767.en

Woods C.M.C. 2002. Natural diet of the seahorse Hippocampus abdominalis. New Zealand Journal of Marine and Freshwater Research 36 (3): 655-660. DOI: $10.1080 / 00288330.2002 .9517121$

Yip M.Y., Lim A.C.O., Chong V.C., Lawson J.M., Foster S.J. 2014. Food and feeding habits of the seahorses Hippocampus spinosissimus and Hippocampus trimaculatus (Malaysia). Journal of the Marine Biological Association of the United Kingdom 95 (5): 1-8. DOI: 10.1017/S0025315414001660

Received: 15 January 2018

Accepted: 5 July 2018

Published electronically: 30 September 2018 